\title{
Defensive burying and approach-avoidance behavior in the rat
}

\author{
JOHN P. J. PINEL, EMELIE HOYER, and L. J. TERLECKI \\ University of British Columbia, Vancouver, British Columbia V6T 1W5, Canada
}

\begin{abstract}
In Experiment 1, rats used bedding to bury a mousetrap (unset) or a flashbulb (unflashed), but not a wooden dowel, when the objects were first encountered in a familiar test chamber. Rats also buried wire-wrapped wooden dowels that had been the source of electric shock (Experiment 2) or wooden dowels dipped in cadaverine (Experiment 3), but they did not bury comparable control objects. In each of the three experiments, the objects that were buried were the same ones that were the focus of approach-avoidance sequences. The fact that both burying and approach-avoidance behavior tended to be directed at the same objects in a variety of situations supports the position that burying behavior in rats, both conditioned and unconditioned, is most appropriately viewed as a defensive response.
\end{abstract}

Pinel and Treit (1978) reported a series of experiments in which rats shocked once through a stationary, wire-wrapped prod mounted on the wall of a test chamber returned to the prod and buried it with commercial bedding material from the floor of the chamber. In each experiment, almost every rat sprayed bedding at the shock source with forward thrusting movements of the forepaws after only a single conditioning trial, even when an identical control prod was mounted on the opposite wall of the chamber or when the shock-test interval was as long as 20 days. Thus, a conditioned association between the shock and the prod appears to control defensive burying in such situations.

Subsequently, Terlecki, Pinel, and Treit (1979) established that burying can also occur as an unconditioned response to novel objects encountered in a familiar environment. When rats first encountered a mouse trap or a flashbulb in a chamber to which they had been habituated, they buried it, whereas rats previously habituated to the trap or the flashbulb did not. In contrast, rats did not bury a stationary, wire-wrapped wooden prod or a length of polyethylene tubing, even on first encounter. However, each rat struck by the trap, shocked by the prod, exposed to an airblast from the tube, or exposed to a flash of the bulb buried the respective source of aversive stimulation, but not a comparable control object, with bedding from the floor of the chamber. Thus, rats seemed to enter the experimental environment with an already established tendency to bury some objects (unconditioned burying), and they readily learned to selectively bury an object that had been the source of any one of a variety of aversive stimuli (conditioned burying).

This research was supported by a Natural Sciences and Engineering Research Council of Canada grant awarded to the first author. For reprints write to John Pinel, Department of Psychology, University of British Columbia, Vancouver, British Columbia V6T 1W5, Canada.
The fact that the burying response is directed at sources of aversive stimulation or at novel objects appearing in familiar environments suggests that burying behavior serves a defensive function. However, McKim and Lett (1979) have recently argued that unconditioned burying of novel objects may be play behavior rather than an adaptive neophobic reaction.

The purpose of the present studies was to provide support for the idea that both conditioned and unconditioned burying serve a defensive function by comparing burying behavior with another behavior commonly found in a variety of aversive situations. The approachavoidance sequence was selected as the subject of this comparison for four reasons. First, this behavior has been unambiguously described in rats by several previous investigators (e.g., Blanchard, Kelley, \& Blanchard, 1974); rats move slowly toward a potentially hazardous object, stop with their bodies extended toward the object (e.g., Grant \& Mackintosh, 1963; Keith-Lucas \& Guttman, 1975), and then finally retreat by backpedaling (e.g., Keith-Lucas \& Guttman, 1975). Second, approach-avoidance behavior occurs in response to both conditioned (a neutral stimulus previously paired with an aversive stimulus) and unconditioned aversive stimuli (Blanchard \& Blanchard, 1970a, 1970b, 1971). Third, like the burying response, the behavior is directed; during approach-avoidance sequences, the rat's body and head are aimed directly at the test object. This feature of approach-avoidance behavior made it possible to determine whether those objects that were buried by the rat were also the focus of approach-avoidance sequences. Fourth, and most important, approachavoidance behavior obviously satisfies both criteria of a defensive response: It occurs reliably in the presence of potentially hazardous stimuli, and it potentially reduces the likelihood of injury. Thus, evidence that burying and approach-avoidance sequences tend to be directed at the same objects would provide support for the view that burying also is a defensive behavior in the rats. 


\section{EXPERIMENT 1}

In Experiment 1, rats were exposed to one of three novel objects, a wire-wrapped prod, a flashbulb, or a mouse trap. Because Terlecki et al. (1979) had found that a trap or bulb, but not a prod, were buried by rats when first encountered in a familiar environment (unconditioned burying), we hypothesized that only the trap and the bulb would be the object of approachavoidance sequences in Experiment 1.

\section{Method}

The 18 naive male 250 - to $300-\mathrm{g}$ hooded rats (Canadian Breeding Farm and Laboratories, La Prairie, Quebec) serving as subjects were housed in groups of four or five in $50 \times 40 \times 20 \mathrm{~cm}$ polyethylene cages lined with a commercial bedding material (San-i-cel, Paxton Processing Company, Paxton, Illinois) made of ground corn cob. Purina Lab Chow and water were continuously available in the home cages.

The prod, trap, and bulb used as stimulus objects in the present study were the same as those employed by Terlecki et al. (1979). The prod was a $6.5 \times .5 \times .5 \mathrm{~cm}$ wooden dowel around which were wrapped two uninsulated wires, and the trap was a $9.8 \times 4.5 \times .5 \mathrm{~cm}$ wooden mousetrap (Victor, Woodstream Corporation, Lilitz, Pennsylvania). The bulb assembly was a standard flashbulb mounted in a gray plastic cylinder $3 \mathrm{~cm}$ in diameter and $5 \mathrm{~cm}$ in length. Although these same objects were used by Terlecki et al. as sources of aversive stimulation, no aversive stimulation was delivered through them in Experiment 1.

On each of the 4 days prior to testing, the rats were placed in the $44 \times 30 \times 44 \mathrm{~cm}$ Plexiglas test chamber in groups of four or five for 30-min habituation sessions. The test chamber floor was covered with a $5-\mathrm{cm}$ layer of San-i-cel bedding during all phases of the experiment. After habituation, the rats were randomly assigned to one of three conditions $(n=6)$ : the trap group, the bulb group, or the prod group. On the test day (i.e., Day 5), each individual rat was placed in the center of the test chamber facing away from the novel object (i.e., trap, bulb, or prod) that had been attached to the middle of one end wall $2 \mathrm{~cm}$ above the level of the bedding.

During the subsequent 15 -min test session, the behavior of each rat was viewed on closed circuit television and recorded on videotape. Two behavioral measures were recorded: the amount of time each rat spent pushing or spraying bedding material toward the test object and the number of times that each rat oriented toward the test object in an extended position and suddenly withdrew from it. To check the reliability of these measures, two observers independently scored the duration of burying and the number of approach-avoidances for 10 randomly selected 5-min segments of the videotaped test sessions. Pearson product-moment correlations revealed high agreement between experienced raters for both duration of burying $(r=.99)$ and number of approach-avoidances $(r=.98)$.

\section{Results}

As hypothesized, there was a positive relation between burying and approach-avoidance behavior (see Figure 1). The rats spent substantially more time burying the trap $[\mathrm{tDunn}(2,15)=2.71, \mathrm{p}<.025]$ or bulb $[\operatorname{tDunn}(2,15)=$ $2.92, \mathrm{p}<.024]$ than they did the prod, and the same pattern was observed in the approach-avoidance data; more approach-avoidance sequences were directed at both the trap $[\operatorname{tDunn}(2,15)=2.74, \mathrm{p}<.025]$ and bulb $[\operatorname{tDunn}(2,15)=2.86, \mathrm{p}<.025]$ than at the prod.
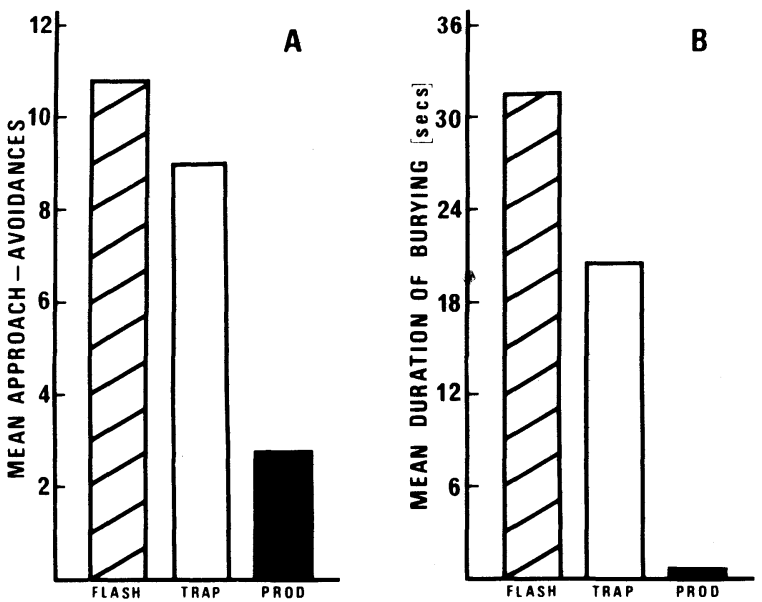

Figure 1. The mean number of approach-avoidances (A) and the mean duration of burying (B) directed at a novel flashbulb, mousetrap, or prod in Experiment 1. No aversive stimulation was administered through any of these objects during Experiment 1.

Because these comparisons were not independent, the increase in probability of making a Type 1 error was controlled for by using the Dunn test and setting the experimentwise error rate at .05 (cf. Keppel, 1973). The overall $(n=18)$ product-moment correlation between the number of approach-avoidances directed at the test object and the duration of burying was $.634(\mathrm{p}<.01)$.

\section{EXPERIMENT 2}

The purpose of Experiment 2 was to demonstrate a relation between conditioned burying and approachavoidance. Do rats shocked by one of two comparable stimulus objects direct both their burying and approachavoidance behavior at the same object?

\section{Method}

The 17 rats serving as subjects were purchased, housed, and habituated as in Experiment 1. On Day 5, one prod was mounted on each end wall $2 \mathrm{~cm}$ above the level of the bedding. The prods were the same as those used in Experiment 1 except that one prod was white and the other black. For eight of the rats (randomly selected), the black prod was designated as the shock source; for the others, the shock was delivered through the white prod. When the rat first touched its designated shock prod with a forepaw, a brief shock, initiated by the experimenter and terminated by the withdrawal of the subject, was delivered between the uninsulated wires wrapped around the prod. The shock circuit was an $800-\mathrm{V}$ current source and an 80,000 -ohm dropping resistor. The termination of the shock marked the beginning of the 15 -min test session.

\section{Results}

Both the burying and approach-avoidance behavior were selectively directed at the shock prod (Figure 2). All 15 of the rats that displayed burying behavior spent more time pushing bedding toward the shock prod than toward the control prod (sign test, $\mathrm{n}=15$, mean $=15$, $\mathrm{p}<.001)$. Approach-avoidance behavior was displayed 
by all 17 rats, and 14 of those directed more of their approach-avoidance sequences at the shock prod (sign test, $\mathrm{n}=17$, mean $=14, \mathrm{p}<.001$ ). Thus, significantly more time was spent burying the shock prod $[\mathrm{t}(32)=$ $5.01, \mathrm{p}<.01]$ and significantly more approach-avoidance sequences were directed at it $[\mathrm{t}(32)=3.61, \mathrm{p}<.01]$.

\section{EXPERIMENT 3}

The results of recent experiments (Pinel, Gorzalka, \& Ladak, Note 1) have shown that rats will bury putridsmelling objects. Although anosmic rats did not, untreated laboratory rats buried wooden dowels soaked with a solution of the nidorous compound cadaverine (1, 5-Diaminopentane), a compound formed by bacterial action on decaying tissue (Cohen, 1971). Will cadaverinesoaked dowels also be the focus of approach-avoidance sequences?

\section{Method}

The methods were the same as those employed in Experiment 2 except that cadaverine rather than shock was the aversive stimulus and the wooden prod was not wrapped with wire. One prod was dipped in cadaverine (Aldrich Chemical Company, Milwaukee, Wisconsin) and mounted on one randomly selected end wall. An identical appearing, but nonodoriferous, control prod was mounted on the wall at the other end. The 15-min test session was initiated when each of the 10 naive rats serving as subjects was placed in the middle of the test chamber. The entire experiment was conducted under a fume hood, and the bedding in the test chamber was changed between subjects.

Results

Every subject spent more time burying the cadaverinedipped prod than the control prod (sign test, $\mathrm{n}=10$,
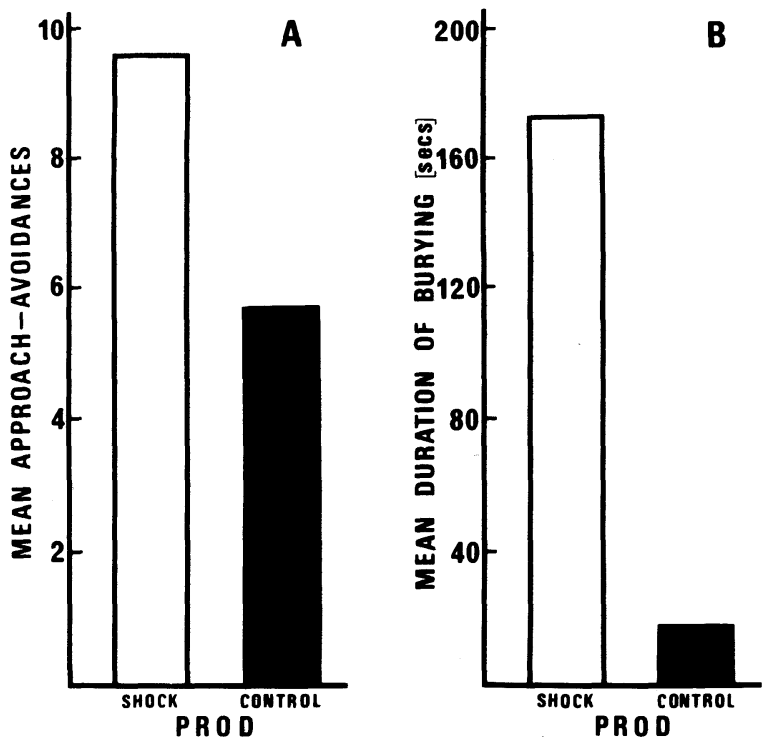

Figure 2. The mean number of approach-avoidances (A) and the mean duration of burying $(B)$ directed at the shock and control prods in Experiment 2.
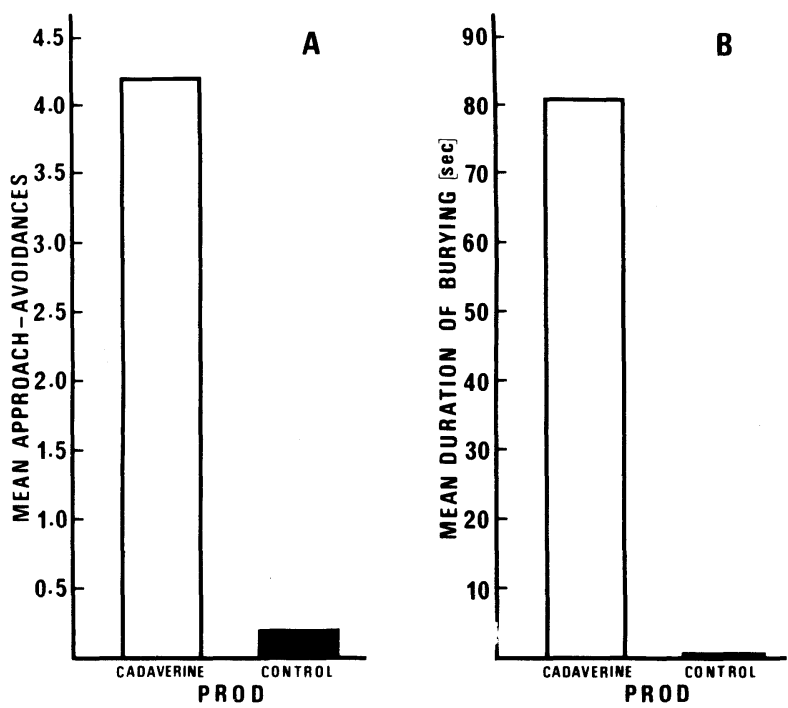

Figure 3. The mean number of approach-avoidances (A) and the mean duration of burying $(B)$ directed at the cadaverinedipped and control prods in Experiment 3.

mean $=10, p<.001]$ and directed more approachavoidance sequences at it (sign test, $\mathrm{n}=10$, mean $=10$, $\mathrm{p}<.001)$. Thus, significantly more time was spent burying the cadaverine-dipped prod $[\mathrm{t}(18)=2.09$, $\mathrm{p}<.05$ ], and significantly more approach-avoidances were directed at it $[\mathrm{t}(18)=5.72, \mathrm{p}<.001]$ (Figure 3 ).

\section{DISCUSSION}

The present experiments provide evidence of a relationship between approach-avoidance and burying behavior in three different situations. In Experiment 1, both unconditioned burying and approach-avoidance behavior were directed at a trap or bulb but not at a stationary, wire-wrapped prod. In the second experiment, both conditioned burying and approachavoidance behavior were directed more at a prod that had been the source of a single footshock than at a comparable control prod. The burying behavior observed in Experiment 3 cannot be unambiguously designated as conditioned or unconditioned, because both the conditioned stimulus (prod) and the unconditioned stimulus (cadaverine) were continuously present throughout testing. However, even in this situation approach-avoidance and burying were related; both were directed at the nidorous prod rather than at the control prod. This relation between burying and approach-avoidance in rats suggests that burying, too, has a defensive function in this species.

There are several ways in which burying behavior could serve a defensive function in rodents. By spraying suitable material at small predators (Hudson, 1950), inanimate objects such as traps (Terlecki et al., 1979), or sources of poison food (Wilkie, MacLennan, \& Pinel, 1979), rodents completely cover these potentially hazardous objects. In other instances, rodents have apparently used the same spraying response to impede the access of aggressive conspecifics (Calhoun, 1962) or members of other species (Terlecki, Pinel, \& Spetch, Note 2) to their burrows or chambers. Owings, Borchert, and Virginia (1977) have reported that forelimb spraying comparable to that observed in the present studies can serve a defensive function even when the accumulation of material is insufficient to cover or block the approach of a predator; California ground squirrels elicit flight 
and other defensive behaviors in snakes by spraying sand at them. Thus, both laboratory experiments and naturalistic observation are consistent with the proposition that the burying behavior of rodents can serve a defensive function.

\section{REFERENCE NOTES}

1. Pinel, J. P. J., Gorzalka, B. B., \& Ladak, F. Cadaverine and putrescine initiate the burial of dead conspecifics by rats. Manuscript submitted for publication, 1980.

2. Terlecki, L. J., Pinel, J. P. J., \& Spetch, M. L. Defensive burying in rat-pigeon confrontations: $A$ videotape presentation. Paper presented at the meeting of the Canadian Psychological Association, Calgary, June 1980.

\section{REFERENCES}

BlanchaRd, R. J., \& BlanchaRd, D. C. Dual mechanisms in passive avoidance: I. Psychonomic Science, 1970, 19, 1-2. (a)

BlanchaRd, R. J., \& Blanchard, D. C. Dual mechanisms in passive avoidance: II. Psychonomic Science, 1970, 19, 3-4. (b)

Blanchard, R. J., \& Blanchard, D. C. Defensive reactions in the albino rat. Learning and Motivation, 1971, 2, 351-362.

Blanchard, R. J., Kelley, M. J., \& Blanchard, D. C. Defensive reactions and exploratory behavior in rats. Journal of Comparative and Physiological Psychology, 1974, 87, 1120-1133.

Calhoun, J. B. The ecology and sociology of the Norway rat. Bethesda, Md: U.S. Department of Health, Education, and Welfare, 1962.
Conen, S. S. Introduction to the polyamines. Englewood Cliffs, N.J: Prentice-Hall, 1971.

Grant, E. C., \& Mackintosh, J. H. A comparison of the social postures of some common laboratory rodents. Behaviour, 1963, 21, 246-259.

Hudson, B. B. One-trial learning in the domestic rat. Genetic Psychology Monographs, 1950, 41, 99-145.

Keith-Lucas, T., \& Guttman, N. Robust single-trial delayed backward conditioning. Journal of Comparative and Physiological Psychology, 1975, 88, 468-476.

KePPEL, G. Design and analysis: $A$ researcher's handbook. Englewood Cliffs, N.J: Prentice-Hall, 1973.

McKıм, W. A., \& LETT, B. T. Spontaneous and shock-induced burying in two strains of rats. Behavioral and Neural Biology, 1979, 26, 76-80.

Owings, D. H., Borchert, M., \& Virginia, R. The behaviour of California ground squirrels. Animal Behaviour, 1977, 25, 221-270.

Pinel, J. P. J., \& Treit, D. Burying as a defensive response in rats. Journal of Comparative and Physiological Psychology, 1978, 92, 708-712.

Terlecki, L. J., Pinel, J. P. J., \& Treit, D. Conditioned and unconditioned defensive burying in the rat. Learning and Motivation, 1979, 10, 337-350.

Wilkie, D. M., Maclennan, A. J., \& Pinel, J. P. J. Rat defensive behavior: Burying noxious food. Journal of the Experimental Analysis of Behavior, 1979, 31, 299-306.

(Received for publication September 3, 1980.) 